\title{
Dinâmica de nitrogênio mineral após alagamento em solos de várzea do Rio Grande do Sul
}

\author{
Mineral nitrogen dynamics after flooding in lowland soils of Rio \\ Grande do Sul
}

\author{
Leandro Souza da Silva ${ }^{1 *}$; Elisandra Pocojeski²; Anderson Clayton Rhoden ${ }^{3}$
}

\begin{abstract}
Resumo
O objetivo deste trabalho foi avaliar a liberação de $\mathrm{N}$ mineral $\left(\mathrm{NH}_{4}^{+} \mathrm{e} \mathrm{NO}_{3}^{-}\right)$em função do tempo após o início do alagamento, em diferentes solos de várzea do RS, e correlacionar as formas de $\mathrm{N}$ mineral com características dos solos. Amostras de 15 solos de várzea do RS foram coletadas em 13 municípios de regiões produtoras de arroz irrigado, as quais foram acondicionadas em tubos de lixiviação e incubadas durante 24 semanas. Durante esse período, foram realizadas lixiviações e determinado o teor de $\mathrm{N}$-mineral. Os teores de $\mathrm{N}_{-} \mathrm{NO}_{3}{ }^{-}$decresceram após o início da incubação e praticamente desapareceram

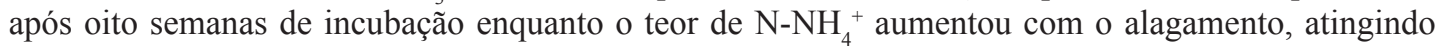
picos ao redor de quatro a cinco semanas de incubação, com posterior declínio até a $18^{\circ}$ semana. Os

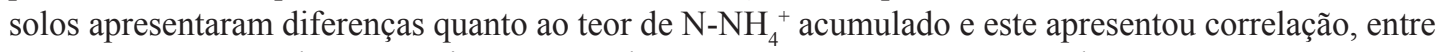

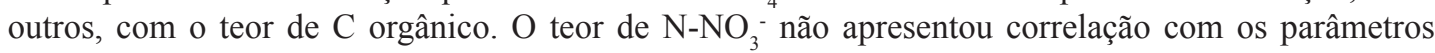
avaliados, exceto com o teor de $\mathrm{N}$ total do solo, e o pico máximo de $\mathrm{N}^{-\mathrm{NH}_{4}^{+}}$apresentou correlação com o teor de $\mathrm{C}$ orgânico e com o $\mathrm{N}^{-\mathrm{NH}_{4}^{+}}$acumulado. Os solos de várzea do $\mathrm{RS}$ podem apresentar diferentes quantidades de $\mathrm{N}_{-} \mathrm{NO}_{3}{ }^{-}$antes do alagamento e se este não for absorvido pelas plantas, poderá ser perdido. $\mathrm{O}$ teor de $\mathrm{N}-\mathrm{NH}_{4}^{+}$acumulado nos solos de várzea apresentou variações relacionadas às características dos solos, principalmente ao teor de $\mathrm{C}$ orgânico.
\end{abstract}

Palavras-chave: Amônio. Nitrato. Incubação-lixiviação.

\begin{abstract}
The present work aims at assessing the releasing of $\mathrm{N}$ mineral in the forms of $\mathrm{NH}_{4}^{+} \mathrm{e} \mathrm{NO}_{3}^{-}$in a due time after the beginning of the flooding in different lowland soils of RS and correlate the forms of $\mathrm{N}$ mineral to the soil characteristics. Samples of 15 lowland soils of RS were collected in 13 cities of flooded rice producing regions. The samples were put into leaching tubes and incubated for 24 weeks. During this period, leaching was carried out and the $\mathrm{N}$-mineral content was determined. The $\mathrm{N}^{-\mathrm{NO}_{3}}$ contents decreased after the beginning of the incubation process and nearly disappeared after 8 weeks of incubation. However, the $\mathrm{N}_{-} \mathrm{NH}_{4}^{+}$content increased with the flooding, reaching peaks around 4 to 5 weeks of incubation, showing a decline until the 18 th week. The soils present differences concerning the content of cumulated $\mathrm{N}_{-} \mathrm{NH}_{4}^{+}$and it presented a correlation, among others, with the organic $\mathrm{C}$

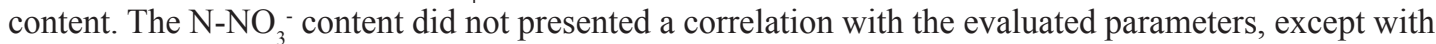
total $\mathrm{N}$ content and, the highest peak of $\mathrm{N}_{-} \mathrm{NH}_{4}^{+}$presented a correlation with the organic $\mathrm{C}$ content

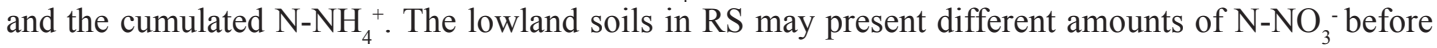

1 Eng $^{\text {o }}$ Agr $^{\circ}$ Dr. Prof. Associado do Departamento de Solos, UFSM, 97105-900, Santa Maria, RS. Bolsista de Produtividade em Pesquisa do CNPq. E-mail: leandro@smail.ufsm.br

2 Eng. Agr ${ }^{\circ}$ M.Sc., Doutoranda do Programa de Pós-Graduação em Ciência do Solo, UFSM, Santa Maria, RS. E-mail: epocojeski@ gmail.com

3 Eng. Agr ${ }^{\circ}$ M.Sc., Prof. do curso de Agronomia da FAI, Faculdade de Itapiranga. Itapiranga, SC. E-mail: andersonrhoden@ hotmail.com

* Autor para correspondência

Recebido para publicação 30/1 1/2009 Aprovado em 09/05/201 1 
the flooding and if it is not absorbed by the plants, it might be lost. The cumulated $\mathrm{N}^{-\mathrm{NH}_{4}+}$ content in lowland soils presented variations related to the soils characteristics, mainly organic $\mathrm{C}$ content.

Key words: Ammonium. Nitrate. Incubation-leaching.

\section{Introdução}

A decomposição e mineralização da matéria orgânica transformam o $\mathrm{N}$ orgânico nas formas amoniacal $\left(\mathrm{NH}_{4}^{+}\right)$e, posteriormente, nítrica $\left(\mathrm{NO}_{3}^{-}\right)$, as quais são aproveitáveis pelas plantas (SCIVITTARO; MACHADO, 2004). A disponibilidade do $\mathrm{N}$ proveniente da MOS durante o crescimento da cultura é uma função principalmente de fatores bióticos e abióticos, incluindo o histórico de cultivo, manejo, clima (temperatura e disponibilidade de água) e a interação com o ciclo do C no solo (GRIFFIN, 2008). Assim, tendo em vista que os fatores que afetam a decomposição e a mineralização são distintos nos solos, a disponibilidade de $\mathrm{N}$ é também bastante variável (SOSBAI, 2005) e, portanto, cada solo possui capacidade intrínseca de fornecer $\mathrm{N}$ a partir da decomposição da MOS.

Nos solos de várzea, a entrada de água para o cultivo do arroz irrigado por alagamento faz com que ocorram alterações químicas, físicas, físicoquímicas e biológicas (SCIVITTARO; MACHADO, 2004) e que a decomposição da MOS seja mais lenta do que em solo bem drenado (ambiente aeróbico). Isto porque um grupo menor e menos eficiente de bactérias é que realizam tal função nestes ambientes anaeróbicos. Entretanto, como tais bactérias exigem menos $\mathrm{N}$ para suas funções vitais, a liberação do elemento no solo é mais rápida em condições alagadas e, após a mineralização, a maior parte do N permanece na forma amoniacal (VAHL, 1999).

Modelos de estimativa da decomposição anaeróbica da MOS tem como base resultados obtidos em experimentos de incubação-lixiviação, na tentativa de descrever matematicamente a dinâmica do $\mathrm{N}$, obtendo a provável liberação do $\mathrm{N}$ da reserva orgânica do solo em um determinado período de tempo (CAMARGO et al., 2002, SILVA et al., 2008). Entretanto, a disponibilidade de $\mathrm{N}$ depende

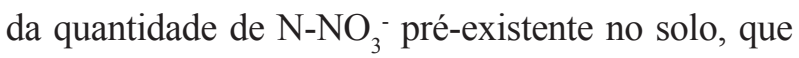

pode ser perdida por desnitrificação (FAGUERIA; STONE; SANTOS, 2003) e da quantidade de $\mathrm{N}-\mathrm{NH}_{4}^{+}$a ser liberada pela decomposição anaeróbica da MOS, uma vez que a nitrificação não ocorre em condições anaeróbicas (VAHL, 1999). A velocidade de desnitrificação depende, principalmente, da presença de material orgânico de fácil decomposição, do tipo de microorganismos envolvidos, do $\mathrm{pH}$ do solo e da temperatura (VAHL; SOUSA, 2004). Já a quantidade de $\mathrm{N}$-mineralizado, em um determinado período, depende de fatores como temperatura, umidade, quantidade e natureza do material orgânico (CAMARGO et al., 2008), o que pode explicar a variada resposta da cultura do arroz irrigado à adubação nitrogenada em solos do RS.

Assim, conhecer a dinâmica de liberação de $\mathrm{N}$ em condições anaeróbias, bem como os parâmetros do solo associados, é de suma importância para determinar a contribuição da MOS no fornecimento de $\mathrm{N}$ à cultura do arroz irrigado, maximizando a utilização do $\mathrm{N}$ do solo potencialmente disponível às plantas. $\mathrm{O}$ objetivo deste trabalho foi avaliar a

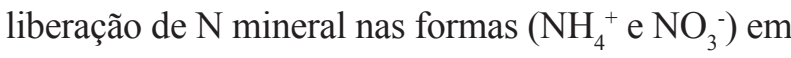
função do tempo após o início do alagamento, para diferentes solos de várzea do RS, e correlacionar as formas de $\mathrm{N}$ mineral com as características do solo.

\section{Material e Métodos}

Foram coletadas amostras de 15 solos de várzea (0-20 $\mathrm{cm}$ de profundidade), em 13 municípios do Estado do RS: Camaquã, Dom Pedrito, Uruguaiana (2 amostras), Caçapava do Sul, Santo Antônio da Patrulha, Santa Maria, São Gabriel, Cachoeirinha, Restinga Seca, Cachoeira do Sul (2 amostras), Santa Vitória do Palmar, Rosário do Sul e Paraíso do Sul. A associação entre os locais de coleta dos solos com as unidades de mapeamento e a classificação brasileira foi realizada de acordo com Streck et al. (2008) (Tabela 1). 
Tabela 1. Classificação, teores de carbono orgânico, argila, nitrogênio total e mineral dos solos utilizados no experimento de incubação-lixiviação.

\begin{tabular}{|c|c|c|c|c|c|c|c|}
\hline \multirow[t]{2}{*}{ Município } & \multirow[t]{2}{*}{$\begin{array}{c}\text { Classificação } \\
\text { Brasileira }\end{array}$} & C org. & Argila & N total & $\begin{array}{r}\mathrm{NO}_{3}^{-} \\
\text {inicial }\end{array}$ & $\begin{array}{c}\mathrm{NH}_{4}^{+} \\
\text {acumulado }\end{array}$ & $\begin{array}{l}\text { Pico } \\
\mathrm{NH}_{4}^{+}\end{array}$ \\
\hline & & \multicolumn{3}{|c|}{ 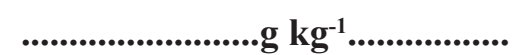 } & \multicolumn{3}{|c|}{$\ldots \ldots \ldots \ldots . . . . . . . . \mathrm{mg} \mathrm{kg}^{-1} \ldots \ldots \ldots \ldots \ldots . . . .}$. \\
\hline$\overline{\text { Camaquã }}$ & Gleissolo Melânico & 37,2 & 800 & 4,2 & 14,0 & 153,5 & 20,2 \\
\hline Dom Pedrito & Gleissolo Háplico & 11,1 & 440 & 3,2 & 19,4 & 65,5 & 9,9 \\
\hline Uruguaiana 1 & Vertissolo Ebânico & 30,9 & 370 & 3,9 & 37,6 & 115,1 & 16,3 \\
\hline Uruguaiana 2 & Chernossolo Ebânico & 20,0 & 330 & 2,6 & 18,2 & 128,0 & 19,3 \\
\hline Caçapava do Sul & Planossolo Háplico & 16,2 & 320 & 2,0 & 12,3 & 107,4 & 16,0 \\
\hline Sto. A. da Patrulha & a Planossolo Háplico & 11,8 & 250 & 1,9 & 13,7 & 96,5 & 14,7 \\
\hline Santa Maria & Planossolo Háplico & 9,5 & 240 & 1,8 & 21,1 & 81,0 & 15,4 \\
\hline São Gabriel & Planossolo Háplico & 13,8 & 230 & 1,8 & 20,1 & 73,2 & 14,4 \\
\hline Cachoeirinha & Gleissolo Háplico & 10,9 & 200 & 1,7 & 11,8 & 80,7 & 17,5 \\
\hline Restinga Seca & Planossolo Háplico & 8,3 & 190 & 1,0 & 11,4 & 58,1 & 11,8 \\
\hline Cachoeira do Sul 1 & 1 Planossolo Háplico & 5,6 & 180 & 1,1 & 9,2 & 72,4 & 12,6 \\
\hline Cachoeira do Sul 2 & 2 Planossolo Háplico & 4,4 & 130 & 0,9 & 12,9 & 70,5 & 12,5 \\
\hline Santa V. do Palmar & r Planossolo Háplico & 9,2 & 120 & 1,3 & 23,3 & 75,7 & 14,0 \\
\hline Rosário do Sul & Planossolo Háplico & 5,5 & 90 & 0,8 & 7,6 & 75,1 & 16,8 \\
\hline Paraíso do Sul & Planossolo Háplico & 7,3 & 80 & 0,7 & 6,7 & 71,1 & 15,6 \\
\hline
\end{tabular}

Os solos receberam aplicação de calcário dolomítico (PRNT 75\%) para elevação e padronização do $\mathrm{pH}$ em 5,5, indicado pelo índice SMP (CQFS RS-SC, 2004). Após, foi realizado um experimento de incubação-lixiviação, com procedimentos e métodos descritos por Rhoden (2005). Os solos alagados foram incubados a uma temperatura de $30^{\circ} \mathrm{C}, \pm 1^{\circ} \mathrm{C}$, em incubadora vertical. Foram realizadas sucessivas extrações da solução de alagamento do solo, sendo estas realizadas semanalmente até a $14^{\circ}$ semana de incubação, quando passaram a ser quinzenais até a $18^{\circ}$ semana de incubação e a cada três semanas até a $24^{\circ}$ e última semana de incubação, totalizando 169 dias de incubação anaeróbia. Uma alíquota de $20 \mathrm{~mL}$ da solução coletada foi levada ao destilador semi-micro Kjedhal para destilação e obtenção do $\mathrm{N}$ mineral $\left(\mathrm{N}_{-} \mathrm{NH}_{4}^{+}\right.$e $\left.\mathrm{N}-\mathrm{NO}_{3}{ }^{-}+\mathrm{N}_{-} \mathrm{NO}_{2}^{-}\right)$, conforme descrito em Tedesco et al. (1995). Considerando que, normalmente, os teores de $\mathrm{N}^{-\mathrm{NO}_{2}}{ }^{-}$são baixos, todo o $\mathrm{N}$ nítrico foi representado pelo $\mathrm{N}_{-} \mathrm{NO}_{3}{ }^{-}$.

Foram realizadas análises de correlação de

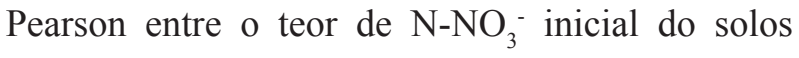
(teores obtidos na primeira semana avaliada), o teor máximo de $\mathrm{N}^{-\mathrm{NH}_{4}}{ }_{4}^{+}$liberado ao longo da avaliação do experimento (independente da semana avaliada) e o teor de $\mathrm{N}^{-\mathrm{NH}_{4}}{ }^{+}$total mineralizado (acumulado no período de avaliação) com o teor de $\mathrm{N}$ total, teor de carbono orgânico e o teor de argila, em nível de $5 \%$ de significância.

\section{Resultados e Discussão}

$\mathrm{O}$ teor de $\mathrm{N}^{-\mathrm{NO}_{3}}$ - diminuiu ao longo do tempo de incubação anaeróbica, desaparecendo, em todos os solos, após a oitava semana de incubação, caracterizando uma ausência de nitrificação em quantidade significativa e/ou uma intensa desnitrificação desta forma de $\mathrm{N}$ presente nos solos (Figura 1a). A intensidade de desnitrificação pode estar relacionada com o teor de MOS de cada solo, pois esta é fornecedora de elétrons às bactérias desnitrificadoras e o $\mathrm{N}^{-\mathrm{NO}_{3}}{ }^{-}$é um dos primeiros compostos oxidados do solo a ser utilizado como receptor de elétrons na respiração anaeróbia 
(SOUSA; CAMARGO; VAHL, 2000).

Pode-se observar que, independente do teor inicial de $\mathrm{N}_{-} \mathrm{NO}_{3}^{-}$, que variou de 6,69 a $37,64 \mathrm{mg}$ $\mathrm{kg}^{-1}$ de solo, na segunda semana todos os solos apresentavam teores muitos próximos, variando de 6,22 a 12,29 $\mathrm{mg} \mathrm{kg}^{-1}$ de solo, ou seja, o processo de desnitrificação foi tão mais intenso quanto

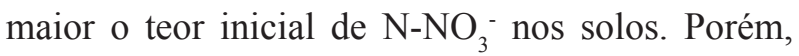
apesar da intensa redução nas primeiras semanas, o $\mathrm{N}_{-} \mathrm{NO}_{3}^{-}$foi detectado até a sétima semana de incubação anaeróbia, indicando que, mesmo após o início do alagamento, ou havia sítios com condições para o processo de nitrificação no solo

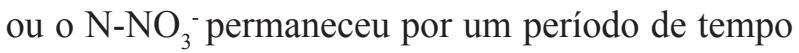
adsorvido no solo até que fosse lixiviado. Segundo Vahl (1999) foram encontradas, em experimentos de campo desenvolvidos no IRRI nas Filipinas, concentrações de aproximadamente $20 \mathrm{mg} \mathrm{L}^{-1}$ de $\mathrm{N}-\mathrm{NO}_{3}{ }^{-}$após 90 dias de alagamento do solo e esta concentração foi mantida praticamente constante desde o início de alagamento. Já Li, Han e Cai (2003), avaliando a mineralização do $\mathrm{N}$ em solos Chineses, encontraram $\mathrm{N}^{-\mathrm{NO}_{3}}{ }^{-}$somente nos dois primeiros dias de incubação anaeróbia, confirmando a predominância de $\mathrm{N}-\mathrm{NH}_{4}{ }^{+}$nestas condições, o que

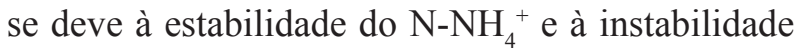

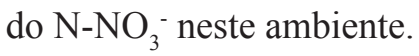

Contrariamente ao teor de $\mathrm{N}_{-} \mathrm{NO}_{3}^{-}$, o teor inicial de $\mathrm{N}^{-\mathrm{NH}_{4}}{ }^{+}$foi muito semelhante para os diferentes solos, aumentando ao longo do tempo de incubação até a quinta semana e, ocorrendo posteriormente, uma diminuição nos teores (Figura 1b). Em experimentos de incubação anaeróbia em laboratório, as taxas de produção de $\mathrm{N}_{-} \mathrm{NH}_{4}^{+}$são altas nos primeiros dias de alagamento e decrescem posteriormente. A intensidade com que os teores diminuem estão associados à características como teor e qualidade da MOS (em relação a suscetibilidade de decomposição) e da temperatura, que aumenta a produção de $\mathrm{N}_{-} \mathrm{NH}_{4}{ }^{+}$como o aumento desta (VAHL, 1999). Como no experimento as condições de temperatura foram mantidas constantes para todos os solos, a mineralização do $\mathrm{N}$ orgânico foi praticamente toda dependente do teor MOS, como pode-se observar, por exemplo, comparando o solo Camaquã com o solo Dom Pedrito, os quais apresentavam 4,17 e 1,24\% de $\operatorname{MOS}(37,2$ e 11,1 $\mathrm{g} \mathrm{kg}^{-1}$ de $\mathrm{C}$ ), respectivamente. O solo Camaquã, além de apresentar maiores teores de $\mathrm{N}_{-} \mathrm{NH}_{4}^{+}$ mineralizado, manteve os teores mais elevados ao longo das avaliações, quando comparado com o solo Dom Pedrito, o que demonstra uma grande influência dos teores de MOS na mineralização do $\mathrm{N}$, nestes casos.

Em relação ao teor de $\mathrm{N}^{-\mathrm{NO}_{3}}{ }^{-}$inicial, este apresentou correlação significativa apenas com o teor de $\mathrm{N}$ total $(\mathrm{r}=0,604)$. Isto se deve principalmente às grandes variações que podem ocorrer com esta forma de $\mathrm{N}$ no solo, mesmo antes do alagamento, já que as amostras foram secas, moídas e incubadas aerobicamente com calcário, o que favorece a liberação de $\mathrm{N}$ e a formação de nitrato.

Para a correlação entre o teor máximo de $\mathrm{N}-\mathrm{NH}_{4}^{+}$liberado (pico de liberação) com os demais parâmetros somente houve correlação significativa com o teor de carbono orgânico, embora o coeficiente de correlação tenha sido baixo $(\mathrm{r}=0,62)$. Ou seja, os picos de liberação de $\mathrm{N}_{-} \mathrm{NH}_{4}^{+}$são explicados parcialmente pelo teor de carbono orgânico, sendo dependente de outro (s) fator (es) não determinados neste experimento, como o $\mathrm{N}$ potencialmente mineralizável e a taxa de mineralização do N (SILVA et al., 2008), e que podem estar relacionados com o curso da redução dos solos. 

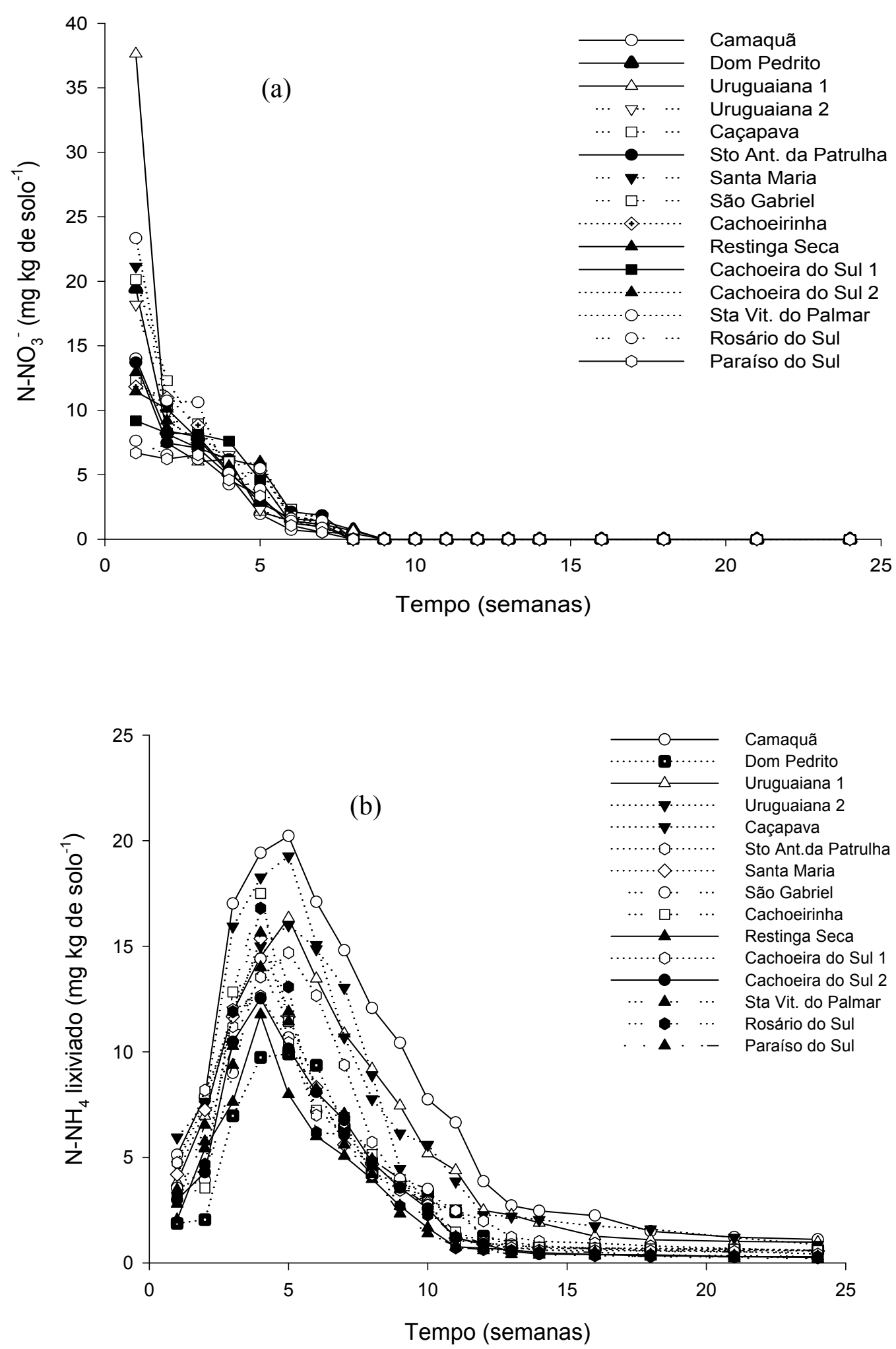

Figura 1. Teor de $\mathrm{N}^{-\mathrm{NO}_{3}}{ }^{-}$(a) e de $\mathrm{N}_{-} \mathrm{NH}_{4}^{+}$(b) na solução de alagamento do solo em função do tempo, para 24 semanas de incubação anaeróbia. 
$\mathrm{O} \mathrm{N}-\mathrm{NH}_{4}^{+}$acumulado apresentou correlação significativa com o teor de argila $(r=0,767)$ e $\mathrm{N}$ total $(\mathrm{r}=0,749)$, porém a maior correlação significativa foi com o teor de C orgânico do solo $(r=0,888)$, confirmando os resultados descritos anteriormente. Como os solos coletados eram de mesmos sistemas de manejo (convencional, com aração e gradagem), onde o predomínio é cultivo de arroz no verão e pousio no inverno, poucas diferenças pode-se esperar em relação a qualidade da MOS, estando a liberação amplamente associada ao teor de carbono e, aparentemente, não a composição deste. A correlação entre o pico de $\mathrm{N}_{-} \mathrm{NH}_{4}{ }^{+}$máximo e o teor acumulado de $\mathrm{N}_{-} \mathrm{NH}_{4}^{+}$também foi significativa ( $\mathrm{r}=$ 0,796), ou seja, resultados obtidos em experimentos de curta duração, desde que obtido o pico máximo de liberação, poderiam ser extrapolados, para obtenção dos resultados do teor total de $\mathrm{N}_{-} \mathrm{NH}_{4}{ }^{+}$a ser liberado. Cabe salientar que, apesar de o teor de $\mathrm{N}-\mathrm{NH}_{4}^{+}$acumulado ter apresentado alta correlação com o teor de $\mathrm{C}$ orgânico, neste experimento, muitas vezes em condições de campo à associação destes parâmetros pode ocorrer de forma diferenciada, já que, o clima, principalmente a temperatura, e o sistema de manejo e de cultivos podem ter influência na liberação de $\mathrm{N}$ às plantas. Os resultados deste experimento vão de encontro ao que é utilizado pela CQFS-RS/SC, para recomendação de N, baseandose nos teores de MOS, porém, em função dos fatores acima citados, há necessidade de confirmar os resultados obtidos em experimentos laboratoriais com experimentos de campo, possibilitando ajustes ou obtenção dos melhores parâmetros para a recomendação de $\mathrm{N}$, à cultura do arroz irrigado.

\section{Conclusões}

Os solos de várzea do $\mathrm{RS}$ têm diferentes quantidades de $\mathrm{N}^{-\mathrm{NO}_{3}}{ }_{3}^{-}$antes do alagamento, que pode ser perdido após o alagamento se não for absorvida pelas plantas de arroz. Coincidentemente com o desaparecimento do $\mathrm{N}^{-\mathrm{NO}_{3}}{ }^{-}$há um pico de liberação de $\mathrm{N}-\mathrm{NH} 4^{+}$, característico para cada solo, sendo que o comportamento de ambos determina a quantidade de $\mathrm{N}$ disponibilizado às plantas para $\mathrm{o}$ arroz irrigado com o alagamento, sendo o valor acumulado relacionado com o teor de C orgânico dos solos.

\section{Agradecimentos}

À CAPES pelas bolsas de pós-graduação e ao CNPq pela bolsa de produtividade em pesquisa.

\section{Referências}

CAMARGO, F. A. de O.; SILVA, L. S. da; GIANELLO, C.; TEDESCO, M. J. Nitrogênio Orgânico do Solo. In: SANTOS, G. A.; SILVA, L. S.; CANELLAS, L. P.; CAMARGO, F. A. O. (Ed.). Fundamentos da matéria orgânica do solo: ecossistemas tropicais e subtropicais. 2. ed. Porto Alegre: Metrópole, 2008. p. 87-97.

CAMARGO, F. A. O.; GIANELlO, C.; TEDESCO, M. J.; RIBOLDI, J.; MEURER, E. J.; BISSANI, C. A. Empirical models to predict soil nitrogen mineralization. Ciência Rural, Santa Maria, v. 12, n. 3, p. 393-399, 2002.

COMISSÃO DE QUÍMICA E FERTILIDADE DO SOLO - RS/SC (CQFS). Manual de adubação e de calagem para os Estados do Rio Grande do Sul e Santa Catarina. 10. ed. Porto Alegre: NRS/SBCS, 2004. 400 p.

FAGUERIA, N. K.; STONE, L. F.; SANTOS, A. B. dos. Manejo da fertilidade do solo para o arroz irrigado. Santo Antônio de Goiás: Embrapa Arroz e Feijão, 2003. $250 \mathrm{p}$.

GRIFFIN, T. S. Nitrogen availability. In: SCHEPERS, J. S.; RAUN, W. R. (Ed.). Nitrogen in agricultural soils. Agronon. Monogr. 49. ASA, CSSA, SSSA, Madison, WI, p. 616-646, 2008.

LI, H.; HAN, Y.; CAI, Z. Nitrogen mineralization in paddy soils of the Taihu region of China under anaerobic conditions: dynamic and model fitting. Geoderma, Amsterdam, v. 115, n. 3, p. 161-175, 2003.

RHODEN, A. C. Potencial de mineralização anaeróbia do nitrogênio em solos de várzea do Rio Grande do Sul. 2005. Dissertação (Mestrado em Ciência do Solo) - Curso de Pós-graduação em Ciência do Solo. Universidade Federal de Santa Maria, Santa Maria.

SCIVITTARO, W. B.; MACHADO, M. O. Adubação e calagem para a cultura do arroz irrigado. In: GOMES, A. da S.; MAGAlHÃES JUNIOR, A. M. de (Org.). Arroz irrigado no Sul do Brasil. Brasília, DF: Embrapa 
Informação Tecnológica, 2004. cap. 9, p. 259-303.

SILVA, L. S.; RHODEN, A. C.; POCOJESKI, E.; CAMARGO, F. O. A.; BENEDETTI, E. Modelos matemáticos para a estimativa do potencial de mineralização anaeróbia do nitrogênio em solos de várzea do Rio Grande do Sul. Revista Brasileira de Ciência do Solo, Viçosa, v. 32, n. 4, p. 1513-1520, 2008.

SOCIEDADE SUL-BRASILEIRA DE ARROZ IRRIGADO - SOSBAI. Arroz irrigado: recomendações técnicas da pesquisa para o Sul do Brasil. In: CONGRESSO BRASILEIRO DE ARROZ IRRIGADO, 4.; REUNIÃO DA CULTURA DO ARROZ IRRIGADO, 26., 2005, Santa Maria, RS. Anais... Santa Maria, RS: Editora, 2005. 159 p.

SOUSA, R. O. de; CAMARGO, F. A. de O.; VAHL, L. C. Solos alagados. In: MEURER, E. J. (Ed.). Fundamentos de química do solo. Porto Alegre: Genesis, 2000. p. 127 150.

STRECK, E. V.; KÄMPF, N.; DALMOLIN, R. S. D.; KLAMT, E.; NASCIMENTO, P. C.; SCHNEIDER, P.; GIASSON, E.; PINTO, L. F. S. Solos do Rio Grande do Sul. 2. ed. Porto Alegre: UFRGS, 2008, 222 p.

TEDESCO, M. J.; GIANELLO, C.; BISSANI, C. A.; BOHNEN, H.; WOLKWEISS, S. J. Análises de solo, planta e outros materiais. 2. ed. Porto Alegre: Departamento de Solos, Faculdade de Agronomia, UFRGS, 1995. 174 p. (Boletim técnico, 5).

VAHL, L. C.; SOUSA, R. O. Aspectos físico-químicos de solos alagados. In: GOMES, A. da S.; MAGALHÃES JUNIOR, A. M. de (Org). Arroz irrigado no sul do Brasil. Embrapa, Brasília, DF, 2004. cap. 4, p. 97-118.

VAHL, L. C. Fertilidade de solos de várzea. In: GOMES, A. S.; PAULETTO, E. A. (Ed.). Manejo do solo e da água em áreas de várzea. Pelotas: Embrapa Clima Temperado, 1999. p. 119-162. 
